Ret. Saude publ., S. Paulo

$12: 67-77,1978$

\title{
SELEÇÃO DE LINHAGENS DE BIOMPHALARIA TENAGOPHILA E BIOMPHALARIA GLABRATA VISANDO MAIOR SUSCETIBILIDADE AO SCHISTOSOMA MANSONI
}

José Valfrido de Santana ** Luiz Augusto Magalhães **

Humberto de Araújo Rangel *

\begin{tabular}{l} 
RSPUB9/395 \\
\hline
\end{tabular}

Santana, J. V. de et al. Seleção de linhagens de Biomphalaria tenagophila $e$ Biomphalaria glabrata visando maior stuscetibilidade ao Schistosoma mansoni. Rev. Saúde públ., S. Paulo, 12:67-77, 1978.

REstuo: Utilizando um esquema de seleção individual em progenies autofecundadas, foram obtidas, após quatro geraçóes, populaçóes de Biomphalaria tenagophila e de Biomphalaria glabrata, altamente suscetiveis às linhagens do Schistosoma mansoni do Vale do Rio Paraiba do Sul, SP e de Belo Horizonte, MG (Brasil), respectivamente. Os rápidos ganhos genéticos obtidos confirmam ser a suscetibilidade de moluscos à infeç̧áo esquistossomótica, uma caracteristica de alta herdabilidade, sendo aparentemente condicionada por um pequeno número de genes.

UNITERMos: Biomphalaria tenagophila. Biomphalaria glabrata. Schistosoma mansani.

I N TRODUCĀO

O estudo das linhagens de Schistosoma mansoni do Vale do Rio Paraíba do Sul (SP) e de Belo Horizonte (MG), descritas por Paraense e Correa12 (1963), e mantidas respectivamente em moluscos planorbideos das espécies Biomphalaria tenagophila e Biomphalaria glabrata, vem despertando o interesse de vários pesquisadores.

Os moluscos $B$. tenagophila têm revelado pouca suscetibilidade à infecção pelo $S$. mansoni, tanto em laboratório, como na natureza (Ruiz 2+, 1957; Martins 10, 1957; Piza e col. 15, 1959; Piza e col. 17.1s, 1960; Coelho: 1962; Bastos: 1975), ainda que vários autores tenham referido indices de infecção mais elevados (Ramos e col. 1", 1961; Paraense e Correa ${ }^{14}, 1963$; Chieffi ${ }^{+}$. $1975)$.

A baixa suscetibilidade da $B$. tenagophila torna dificil a manutenção do ciclo do $S$. mansoni da linhagem paulista em laboratório, e conseqüentemente, prejudica os trabalhos de patologia, imunologia e outros estudos de biologia, envolvendo essa linhagem.

A suscetibilidade de moluscos à infecção pelo S. mansoni é um carácter altamente hereditário (Newton ${ }^{11}, 1953$; Richards 21,

* Trabalho realizado com auxilio da FAPESP e do CNPa.

** Do Instituto de Biologia da Universidade Estadual de Campinas (UNICAMP) - Caixa Postal 1170 - Campinas, SP - Brasil. 
SANTANA, J. V. de et al. Seleção de linhagens de Biomphalaria tenagophila e Biomphalaria glabrata visando maior suscetibilidade ao Schistosoma manisoni. Rev. Saúde públ., S. Paulo, $12: 67-77,1978$.

1970; Richards 22, 1973; Richards 20, 1975; Richards e Merritt 23, 1972). Com base nessas informações, propusemo-nos, neste trabalho, selecionar indivíduos em progenie derivadas por autofecundação, das populações de $B$. tenagophila e de $B$. glabrata, visando aumentar a suscetibilidade às linhagens simpáticas do $S$. mansoni, respectivamente do Vale do Rio Paraíba e de Belo Horizonte.

\section{MATERIAL E METODOS}

1. Procedência e esquema de seleção de moluscos das espécies B. tenagophila $e$ B. glabrata.

Os moluscos B. tenagophila da geração parental eram descendentes diretos de caramujos capturados no Vale do Rio Paraíba do Sul (SP).

Os exemplares correspondentes da espécie $B$. glabrata eram descendentes diretos de caramujos capturados em Belo Horizonte (MG).

A linhagem de $S$. mansoni do Vale do Paraiba, representaremos pela sigla "SJ" (por ter sido isolada inicialmente em São José dos Campos), e a de Belo Horizonte, pela sigla "BH".

Foi separado, aleatoriamente, um grupo de trinta moluscos por espécie, para formar a geração parental. Estes molucos foram submetidos à infecção pelas linhagens simpátricas do $S$. mansoni. Dos indivíduos infectados, obtivemos, por autofecundação, a geração $F_{1}$. Procedimento semelhante foi realizado em todas as gerações estudadas, utilizando-se sempre trinta moluscos por geração.

$\mathrm{Na}$ Fig. 1 resumimos a metodologia utilizada para a seleção de populações de $B$. tenagophila e $B$. glabrata, suscetiveis à infecção pelo $S$. mansoni.
2. Obtenção de miracidios das linhagens paulistas (SJ) e mineira (BH) do S. mansoni. Infecção de planorbídeos. Obtenção e contagem de cercárias.

Miracídios das linhagens SJ e $\mathrm{BH}$ foram obtidos de fígados de camundongos sacrificados no $60^{\circ}$ dia contado a partir da data de exposição às cercárias. Os fígados foram homogenizados em liquidificador, obtendo-se uma suspensão que era submetida a passagem através de peneiras "GRANUTEST", com malhas de 0,037, 0,074 e $0,149 \mathrm{~mm}$.

A suspensão contendo os granulomas retidos na malha de $0,037 \mathrm{~mm}$ era transferida para placas de Petri, e colocada du-

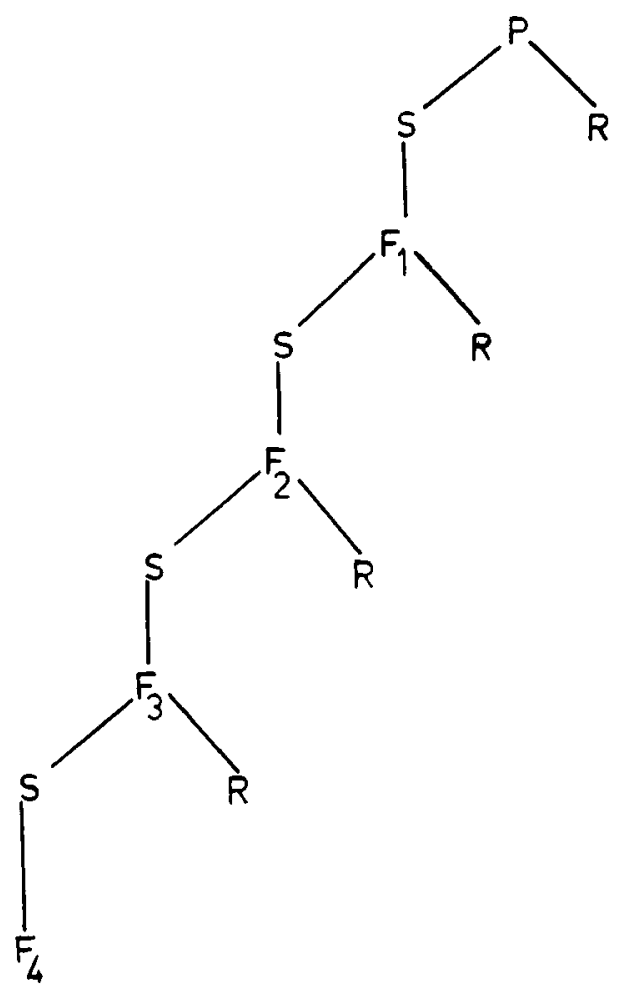

Fig. 1 - Esquema de seleção para a obtenção de populações de moluscos das espécies $B$. tenagophila e $\boldsymbol{B}$. glabrata, suscetíveis ao $\boldsymbol{S}$. mansoni. (30 moluscos por geração para cada espécie). $\mathbf{S}=$ suscetiveis; $\mathbf{R}=$ resistentes. 
SANTANA, J. V. de et al. Seleção de linhagens de Biomphalaria tenagophila e Biomphalaria glabrata visando maior suscetibilidade ao Schistosoma marisoni. Rev. Saúde públ., S. Paulo, $12 ; 67-77,1978$

rante cerca de 20 min., sob a ação de lâmpadas elétricas, de modo a fornecer temperatura de $28^{\circ} \mathrm{C}$ e luminosidade suficiente para a eclosão dos miracídios (Standen 2*, 1951). Os miracídios, assim obtidos, foram utilizados para a infeç̧ão de moluscos da geração parental.

Moluscos jovens de ambas as espécies, medindo entre 7 e $8 \mathrm{~mm}$ de diâmetro, foram expostos individualmente a 10 miracidios, segundo técnica de Standen ${ }^{26}$ (1952).

Para a exposiçāo aos miracidios, os moluscos foram divididos em dois lotes, conforme transcrito abaixo.

Lote I - constituido por 30 B. tenagophila . expostos a miracídios da linhagem paulista (SJ).

Lote 11 - constituido por $30 \mathrm{~B}$. glabrata expostos a miracídios da linhagem mineira $(\mathrm{BH})$.

Os miracidios utilizados para a infecção dos caramujos das geraçōes $F_{1}, F_{2}, F_{3}$ e $\mathrm{F}_{4}$ eram procedentes de figados de camundongos infectados con cercárias obtidas de moluscos das gerações anteriores.

Após 30 dias da exposição aos miracidios, os moluscos eram examinados semanalmente, sendo expostos a luz artificial, para obtenção de cercárias, segundo técnica descrita por Pellegrino e Macedo1.5 (1955). Foi realizada uma estimativa das cercárias eliminadas por cada molusco, adotando-se critério baseado na técnica de Alvim ${ }^{1}$ (1974).

Decorridos cem dias, os moluscos que permaneciam negativavos eram esmagados entre lâminas de vidro, e examinados ao microscópio estereoscópico, a fim de detectarmos a presença de possiveis esporocistos retardatários.

Empregamos metodologia semelhante a descrita acima, para as geraçōes $F_{1}, F_{2}, F_{3}$ e $F_{4}$ de ambas as espécies de planorbídeos.
Para eteito de controle, formamos um lote de 30 moluscos por espécie, não selecionados quanto a suscetibilidade à infecção esquistossomótica. Estes moluscos não foram expostos a miracidios, sendo mantidos isolados durante cem dias. $O$ objetivo desse grupo controle era demonstrar que os indices de mortalidade encontrados eram devidos à infecção dos moluscos pelo $S$. mansoni, e não a fatores técnicos ou ambientes.

\section{RESULTADOS}

Utilizando metodologia resumida na Fig. 1, foram obtidas quatro geraçōes para cada uma das espécies de moluscos estudadas. A suscetibilidade desses moluscos à infecção pelas linhagens simpátricas do $S$. mansoni aumentou sensivelmente, desde a geração $F_{1}$ para $B$. glabrata, e a partir da geração $\mathrm{F}_{2}$ para $B$. tenagophila. Nas Figs. 2 e 3 podemos verificar o rápido progresso de seleção, no jsolamento de populaçōes altamente suscetiveis de $B$. tenagophila e de $B$. glabrata.

De acordo com os dados apresentados nas Tabelas 2 e 3, podemos observar que da taxa de $6,6 \%$ de infecção para $B$. tenagophila na geração parental, passamos para $96,6 \%$ na geração $F_{2}$. Em $B$. glabrata passamos da taxa de $40,0 \%$ de infecção na geração parental para $93,3 \%$ na geração $F_{1}$.

As taxas de mortalidade, nas várias gerações estudadas, variaram entre $16,6 \%$ a $50,0 \%$ para $B$. tenagophila, e entre $33,3 \%$ a $73,3 \%$ para $B$. glabrata (Figs. 4 e 5 ).

No lote controle verificamos taxas de mortalidade de $13,3 \%$ em $B$. glabrata, durante o período de cem dias; enquanto que em $B$. tenagophila não constatamos mortalidade, no mesmo período. Os dados referentes a estes estudos acham-se agrupados na Tabela 3 . 
SANTANA, J. V. de et al. Seleção de linhagens de Biomphalaria tenagophila e Biomphalaria glabrata visando maior suscetibilidade ao Schistosoma mansoni. Rev. Saúde públ., S. Paulo, $12: 67-77,1978$.

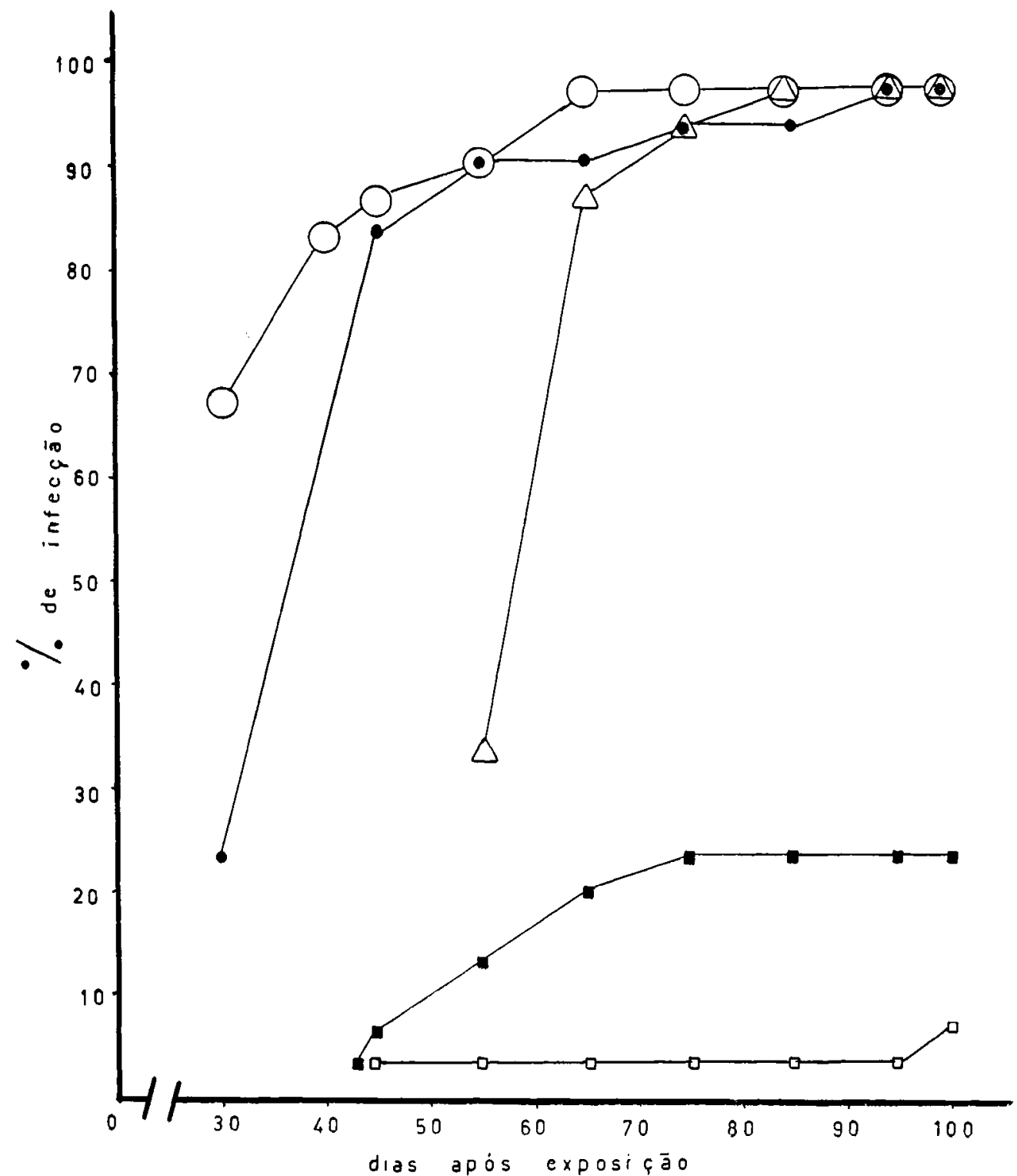

Fig. 2 - Infeç̧ão obtida após exposição de exemplares de $B$. tenagophila a miracídios da linhagem SJ de S. Mansoni. Gerações: $\mathbf{P} \square: \mathrm{F}_{\mathrm{L}} \mathbf{Z}: \mathrm{F}_{2} \mathrm{O}: \mathrm{F}_{3} \bullet ; \mathrm{F}_{4} \Delta$. 
SANTANA, J. V. de et al. Seleção de linhagens de Biomphalaria tenagophila e Biomphalaria glabrata visando major suscetibilidade ao Schistosoma manisoni. Rev. Saúde públ., S. Paulo, $12: 67-77,1978$.

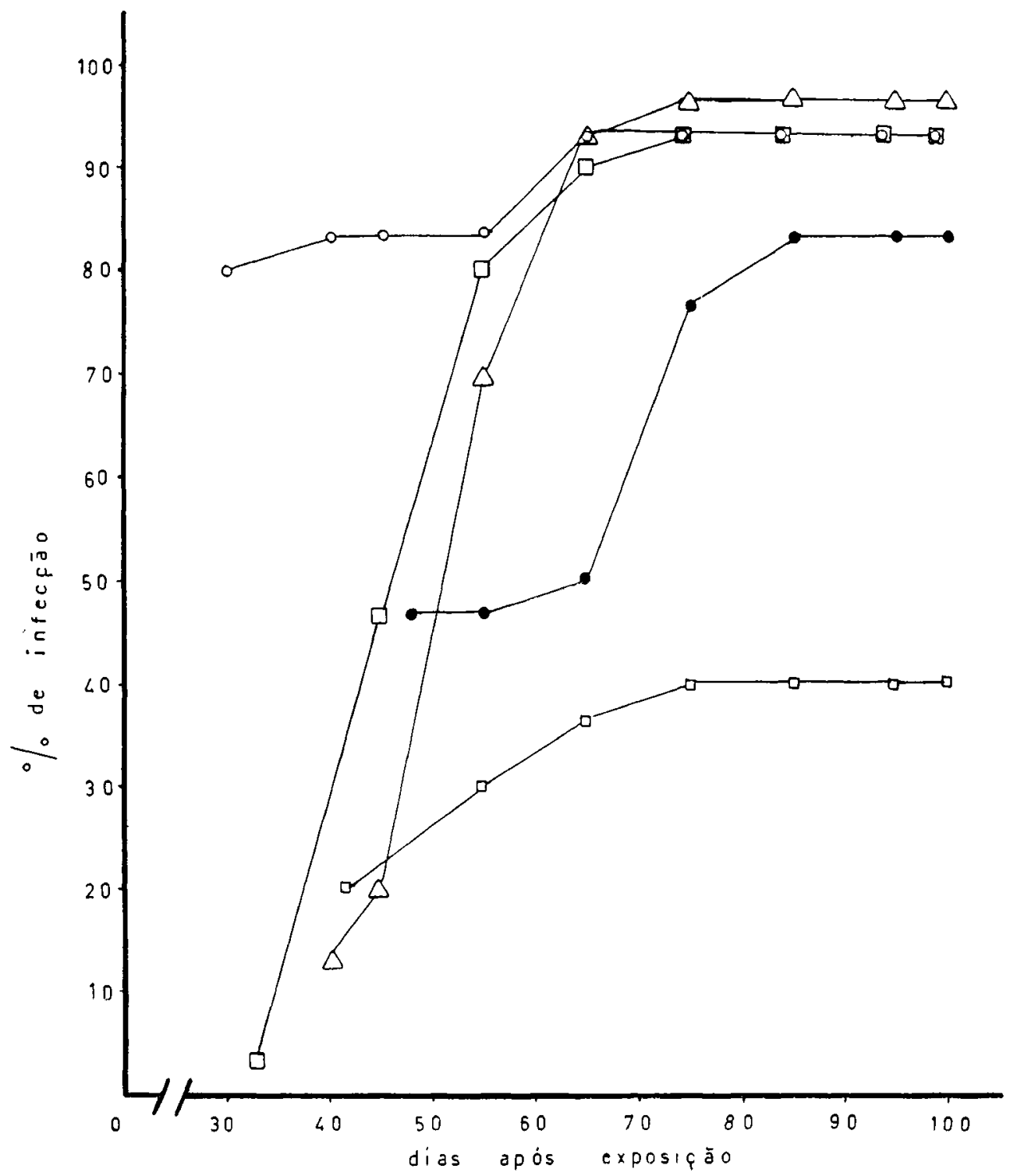

Fig. 3 - Infecção obtida após exposição de exemplares de $B$. glabrata a miracidios da linhagem BH de $s$. mansoni. Gerações: $P \square \cdot F_{1} \square ; F_{: 2} O F_{:} \bullet \cdot F_{1} \triangle$. 
SANTANA, J. V, de et al. Seleção de linhagens de Biomphalaria tenagophila e Biomphalaria glabrata visando maior suscetibilidade ao Schistosoma mansoni. Rev. Saude públ., S. Paulo, $12: 67-77$. 1978 .

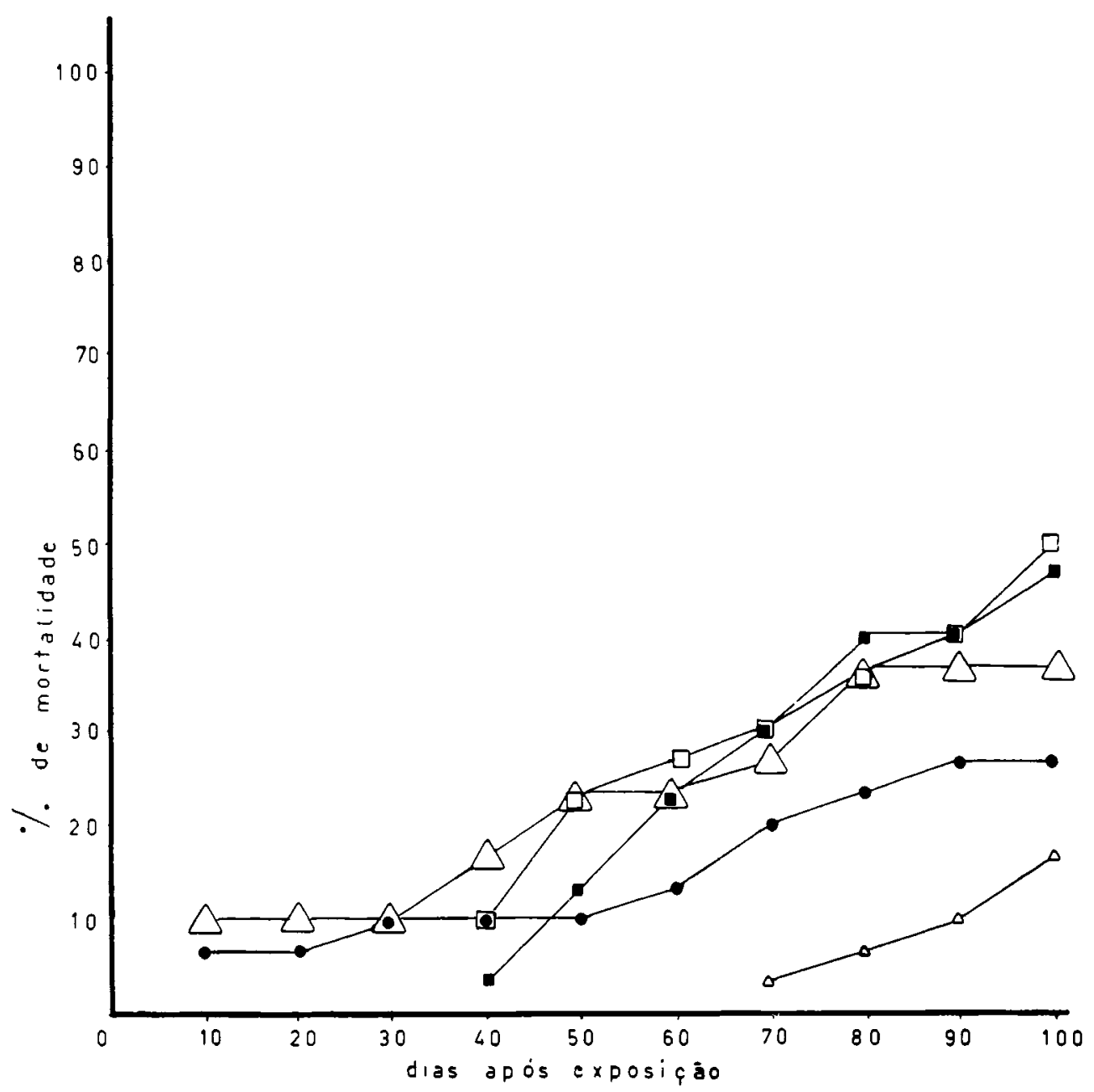

Fig. 4 - Mortalidade obtida após exposição de exemplares do B. tenagophila a miracidios da linhagem SJ de S. mansoni. Geraçōes: $\mathrm{P} \triangle \cdot \mathrm{F}_{1} \cdot \mathrm{F}_{2} \square \cdot \mathrm{F}_{3} \square: \mathrm{F}_{4} \Delta$. 
SANTANA, J. V. de et al. Seleção de linhagens de Biomphalaria tenagophila e Biomphalaria glabrata visando maior suscetibilidade ao Schistosoma manisoni. Rev. Saúde públ., S. Paulo, $12: 67-77,1978$.

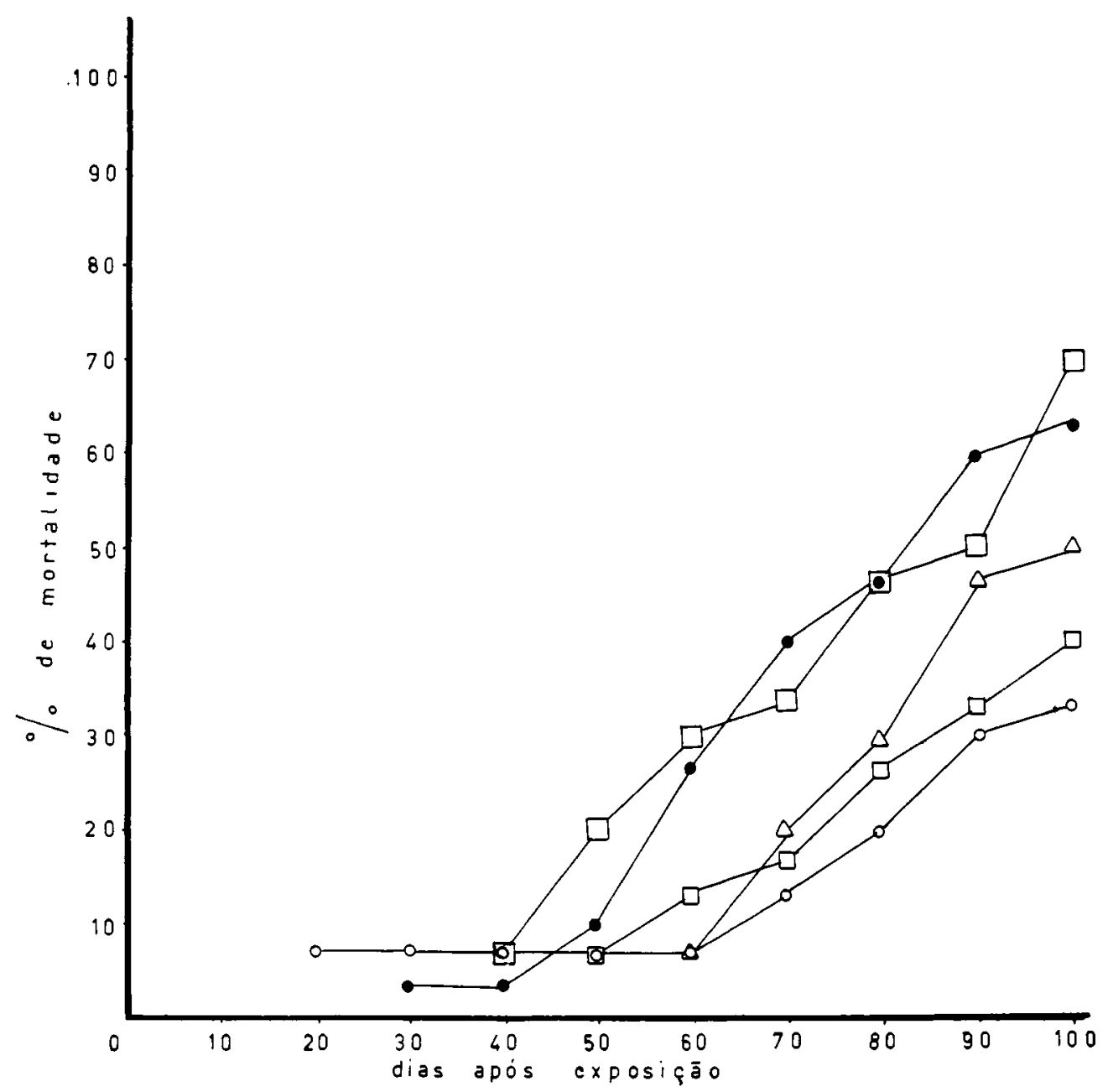

Fig. 5 - Mortalidade obtida após exposição de exemplares de $B$, glabrata a miracídios da linhagem $\mathbf{B H}$ de $S$. mansoni. Gerações: $P O: F_{1} \bullet: F_{0} \square \cdot F_{2} \square \quad: F_{4} \Delta$. 
SANTANA. J. V, de et al. Seleção de linhagens de Biomphalaria tenagophila e Biomphalarm glabrata visando maior suscetibilidade ao Schistosoma maisoni. Rer. Saride píbl., S. Paulo. $12: 67-77,1978$

T A B EL A 1

Rosultados obtidos no $100^{\circ}$ dia da exposição de B. tenagophila a linhagem de S. mansoni (Lotes de 30 moluscos por geração, e exposição a 10 miracídios por molusco).

\begin{tabular}{cccccc}
\hline Geraçöes & $\begin{array}{c}\text { Molucos } \\
\text { Infectados }\end{array}$ & $\begin{array}{c}\text { Percentagem } \\
\text { de moluscos } \\
\text { infectados }\end{array}$ & Mortalidade & $\begin{array}{c}\text { Total de } \\
\text { cercárias } \\
\text { eliminadas }\end{array}$ & $\begin{array}{c}\text { Cercárias } \\
\text { moluscos } \\
\text { infectados }\end{array}$ \\
\cline { 5 - 6 } $\mathrm{P}$ & $\mathrm{n}^{0}$ & $\%$ & $\%$ & $\mathrm{n}^{\circ}$ & no \\
$\mathrm{F}_{1}$ & 2 & 6,6 & 36,6 & 2.412 & 1.206 \\
$\mathrm{~F}_{2}$ & 7 & 23,3 & 23,3 & $\mathbf{1 8 . 8 0 0}$ & 2.686 \\
$\mathrm{~F}_{3}$ & 29 & 96,6 & 46,6 & $\mathbf{4 5 . 8 8 6}$ & 1.582 \\
$\mathrm{~F}_{4}$ & 29 & 96,6 & 50,0 & $\mathbf{4 0 . 9 9 3}$ & 1.413 \\
& 29 & 96,6 & 16,6 & $\mathbf{5 3 . 3 8 7}$ & 1.841 \\
\hline
\end{tabular}

T A B E L A 2

Resultados obtidos no $100^{\circ}$ dia da exposição de B. glabrata a linhagem BH de S. mansoni (Lotes de 30 moluscos por geração, e exposição a 10 miracídios por molusco).

\begin{tabular}{cccccc}
\hline Geraçós & Moluscos & $\begin{array}{c}\text { Percentagem } \\
\text { de moluscos } \\
\text { infectados }\end{array}$ & Mortalidade & $\begin{array}{c}\text { Total de } \\
\text { cercárias } \\
\text { eliminadas }\end{array}$ & $\begin{array}{c}\text { Cercárias/ } \\
\text { molusco } \\
\text { infectado }\end{array}$ \\
\hline $\mathrm{P}$ & 12 & $\%$ & $\%$ & $\mathrm{n}$ \% & $\mathrm{n}^{\prime}$ \\
$\mathrm{F}_{1}$ & 28 & 90,0 & 33,3 & 30.805 & 2.567 \\
$\mathrm{~F}_{2}$ & 28 & 93,3 & 63,3 & 100.438 & 3.587 \\
$\mathrm{~F}_{3}$ & 25 & 83,3 & 40,0 & 224.234 & 8.000 \\
$\mathrm{~F}_{4}$ & 29 & 96,6 & 73,3 & 79.924 & 3.197 \\
\hline
\end{tabular}

T A B E L A

Mortalidade para moluscos não infectados por S. mansoni e não selecionados quanto a suscetibidade à infeç̧ão esquistossomótica (Período de observação - 100 dias).

\begin{tabular}{lcc}
\hline Espécies & $\begin{array}{c}\text { Total de } \\
\text { moluscos }\end{array}$ & Mortalida`e \\
\hline & $\mathrm{n}^{\circ}$ & $\%$ \\
B. tenagophila & 30 & 0,0 \\
B. glabrata & 30 & 13,3 \\
\hline
\end{tabular}

Nas Tabelas 1 e 2 apresentamos, também, o número médio de cercárias eliminadas por molusco, em cada geração.
O exame dos moluscos que até o 100 " dia, a contar da data de exposição aus miracidios, não haviam eliminado cercárias não revelou nenhuma forma larvária du verme.

\section{DISCUSSĀO}

Entre os importantes fatores que determinam a infecção de moluscos pelo $S$. mansoni estão aqueles de natureza genética. Newton 11 (1953) e Richards 21 (1970) demonstraram que a suscetibilidade de $B$. glabrata ao $S$. mansoni era un caráter altamente hereditário. Richards e Merritt². (1972) sugeriram que a suscetibilidade dos 
SANTANA, J. V, de et al. Seleção de linhagens de Blomphalaria tenagophila e Biomphalaria glabrata visando maior suscetibilidade ao Schistosoma marisoni, Rer. Saude pübl.. S. Paulo, $12: 67-77,1978$.

moluscos ao $S$, mansoni é provavelmente controlada por quatro pares de fatores genéticos.

A suscetibilidade à infecção pelo $S$. mansom, entretanto, varia com a idade dos moluscos hospedeiros (Newton ${ }^{11}, 1953$; Wright 2", 1963; Richards "*, 1973), sendo os moluscos jovens mais suscetiveis.

Por outro lado, existe uma grande variabilidade de dados encontrados na literatura, com relação a idade e tamanho de moluscos por ocasião da maturidade sexual, fato este, devido, sobretudo, à diversidade das condições de ambiente e alimentação.

Com a finalidade de trabalharmos apenas com moluscos jovens, determinamos, inicialmente, sob nossas condiçōes de laboratório, a época da maturidade sexual em moluscos das espécies $B$. tenagophila e $B$. glabrata. Baseados nestes resultados preliminares, expusemos aos miracidios apenas os moluscos que ainda não haviam atingido a maturidade.

Os dados referentes a $B$. glabrata mostraram que mesmo a geração parental apresentou uma elevada suscetibilidade, demonstrando que estes moluscos já sāo bem adaptados à infecção esquistossomótica. Estes resultados confirmam aqueles encontrados por Paraense e Correa ${ }^{13}, 1963$; Magalhães 8.9, 1ऽ69, 1970; Chieffi 4, 1975.

A queda percentual de infecção em $B$. glabrata da geração $\mathrm{F}_{: ;}$em relação as gerações $F_{2,}$ e $F_{4}$, pode-se justificar pelo fato de ter ocorrido a morte de cinco moluscos, antes de completado o periodo de observaçóes. Apesar de não nos ter sido possível constatar a infecção esquistossomótica nestes moluscos, verificamos uma perda de capacidade de reprodução destes planorbídeos, sendo esta uma indicação positiva de que provavelmente estavam infectados. A redução da capacidade reprodutora em moluscos infectados, por nós verificada, concorda com os achados de vários autores (Brumpt ${ }^{3}$, 1941; Coelho ${ }^{5}$ 1954; Sturrock e Sturrock "* 1970).

Em relação a $B$. tenagophila, verificamos que a geração parental apresentou grande resistência à infecção pelo S. mansoni. Dos 30 moluscos expostos aus miracidios, apenas dois mostraram-se infectados no $100^{\text {: }}$ dia. Após a seleçâo em progenies autofecundadas, conseguimos isolar populaçóes de $B$. tenagophila altamente suscetiveis a infecção simpátrica. Mesmo assim, estas populaçōes apresentaram comportamento diferente com relação as populações estudadas de $B$. glabrata, no que diz respeito ao numero de cercárias eliminadas por molusco. Enquanto que para $B$. glabrata obtivemos até 13.000 cercárias por molusco, para $B$. tenagophila, o máximo obtido foi de aproximadamente 2.700 cercárias por molusco. Essa menor produção de cercárias verificada em moluscos da espécie $B$. tenagophila em relação a $B$. glabrata, devese provavelmente a mecanismos de imunidade natural. Coelho $6 . \bar{i}(1957,1962)$ verificou grande resistência apresentada pelos tecidos de $B$. tenagophila aos esporocistos do S. mansoni, provocando geralmente a lise dessas larvas nos primeiros dias após exposição aos miracídios. Em B. glabrata, esse mesmo autor verificou pequuena reação tecidual a penetração e evolução do trematódeo.

Nossos resultados confirmam ser a suscetibilidade uma caracteristica altamente hereditária, condicionada aparentemente por um pequeno número de genes. Evidência nesse sentido é dada pelo rápido progresso de seleção, mesmo na presença de alta taxa de "inbreeding".

\section{CONCLUSÃo}

Os dados obtidos indicam que é possivel obter modificações substanciais dos graus de suscetibilidade à infecção pelo $S$. mansoni, em populaçóes de moluscos planorbídeos, através de seleção individual de progenies derivadas por autofecundação.

\section{AGRADECIMENTOS}

Ao Professor William José da Silva, geneticista do Instituto de Biologia da UNICAMP, pela revisão e sugestões apresentadas. 
SANTANA, J, V, de et al. Seleção de linhagens de Biomphalaria tenagophila e Biomphalaria glabrata visando maior suscetibilidade ao Schistosoma mansoni. Rev. Saúde públ., S. Paulo, $12: 67-77,1978$.

RSPUB9/395

SANTANA, J. V. de et al. /Selection of strains of Biomphalaria tenagophila and Biomphalaria glabrata to improve susceptibility to Schistosoma mansoni.I Rev. Saúde públ., S. Paulo, 12:67-77, 1978.

ABSTRACT: Populations of B. tenagophila and B. glabrata highly susceptible to strains S. mansoni from the Valley of the Paraiba do Sul River (State of S. Paulo) and from Belo Horizonte (State of Minas Gerais), were obtained" after four generations using a schedule of individual selections in self-fertilized populations. The rapid genetic gains in susceptibility show that molluscan susceptibility to schistosomiasis infection is highly inheritable, and is apparently, conditioned by few genes. mansoni.

UNITERMS: Biomphalaria tenagophila - Biomphalaria glabrata. Schistosoma

\section{REFERENCIAS BIBLIOGRAFICAS}

1. ALVIM, M. C. Suscetibilidade de B. glabrata e B. straminea do Maranhão a uma cepa simpátrica de Schistosoma mansoni, Belo Horizonte, 1974. [Tese - Instituto de Ciências Biologicas Univ. Federal de Minas Gerais].

BASTOS, O. de C. Estudo do comportamento parasitológico e imunológico das linhagens humana e silvestre do Schistosoma mansoni Sambon, 1907. Campinas. 1975. [Tese - Instituto de Biologia da Universidade Estadual de Campinas]

3. BRUMPT, E. Observations biologiques diverses concernant Planorbis (Australorbis) glabratus hôte intermédiaire de Schistosoma mansoni. Ann. Parasitol., 18(1/3):9-45, 1941

4. CHIEFFI. P. P. Suscetibilidade à infecção por Schistosoma mansoni, de cepas de Biomphalaria tenagophila originárias dos Estados de São Paulo e Paraná. Rev. Inst. Med. trop. S. Paulo, 17: 92-6. 1975 .

5. COELHO. M. V. Ação das formas larvárias de Schistosoma mansoni sobre a reprodução de Australorbis glabratus. Publ. Avul. Inst. Aggeu Magathães, 3:39-54. 1954.

6. COELHO. M. V. Aspectos do desenvolvimen. to das formas larvais de Schistosoma mansoni em Australorbis nigricans. Rer. bras. Biol., 17:325-37, 1957.

7. COELHo, M. V. Suscetibilidade de Australorbis tenagophilus à infecção por Schistosoma mansoni. Rev. Inst. Med. trop, S. Paulo, 4:289-95, 1962.
8. Magalhaes. L. A. Estudo dos dados obtidos de uma população de Biomphalaria glabrata de Belo Horizonte infectada por Schistosoma mansoni da mesma cidade, e de uma população de $B$, tenagophila de Campinas, infectada por S. mansoni đe São José dos Campos. Rev. Soc. bras. Med. trop., 3: 195-6. 1969.

9. MAGALHAES, L, A. Estudo do comportamento da cepa de $S$. mansoni de Brasília. Hospital, Rio de Janeiro, 77 : 273-83, 1970.

10. MARTINS, R. S. Focos ativos de esquistossomose em Niterói. Estado do Rio de Janeiro. Rev. bras. Malar., 9:361-4. 1957.

11. NEWTON, W. L. The inheritance of susceptibility to infection with Schistosoma mansoni in Australorbis glabratus, Exp. Parasit, 2:242-57, 1953.

12. PARAENSE, W. L. \& CORREA. L. R. Sobre a ocorrência de duas raças biológicas do Schistosoma mansoni no Brasil. [Apresentado na XV Reunião da Sociedade Brasileira para o Progresso da Ciencia, Campinas, 1963]

13. PARAENSE, W, L. \& CORREA, L. R. Variation in susceptibility of population of Australorbis glabratus to a strain of Schistosoma mansoni. Rer. Inst. Med. trop. S. Paulo, 5:15-22. 1963.

14. PARAENSE. W, L. \& CORReA. L. R. Susceptibility of Australorbis tenagophilus to infection with Schistosoma mansoni. Rev. Inst. Med. trop. $\mathbf{s}$. Paulo, 5:23-9, 1963. 
SANTANA, J, V, de et al, Seleção de linhagens de Biomphalaria tenagophila e Biomphalaria glabrata visando maior suscetibilidade ao Schistosoma marisoni. Rev. Saúde públ, S. Paulo, $12: 67-77,1978$

15. PELlEgrino, J. \& MACEDO, D. G. A simplified method for the concentration of cercariae. J. Parasit., 41:329-30, 1955.

16. PIZA, J. T. et al. A esquistossomose no vale do Paraíba. Rev. Inst. Adolfo Lutz, 19:97-143, 1959.

17. PIZA, J. T. et al. Vale do Paraíba, foco endêmicio de esquistossomose. Arq. Hig., S. Paulo, 25:35-40, 1960.

18. PIZA, J. T. \& RAMOS, A. S. Os focos autóctones da esquistossomose no Estado de São Paulo. Arq. Hig., S. Paulo., 25:261-71, 1960.

19. RAMOS, A. S. et al. Observações 'sobre Australorbis tenagophilus, transmissor da esquistossomose mansônica. Arq. Hig., S. Paulo, 26:121-4, 1961.

20. RICHARDS, C. S. Genetic factors in susceptibility of Biomphalaria glabrata for different strains of Schistosoma mansoni. Parasitology, $70: 231-41,1975$

21. RICHARDS, C. S. Genetics of a molluscan vector of Schistossomiasis. Nature, 227 : 806-10, 1970.

22. RICHARDS, C. S. Susceptibility of adult Biomphalaria glabrata to Schistosoma mansoni infection. Amer. J. trop. Med. Hyg., 22:748-56, 1973.

23. RICHARDS, C. S. \& MERRITT, J. W. Genetic factors in the susceptibility of juvenile Biomphalaria glabrata to Schistosoma mansoni infection. Amer. J. trop. Med. Hyg., 21:425-34, 1972.
24. RUIZ, J. M. Esquistossomose experimental. 5. Dados sobre a infestação experimental de "Biomphalaria tenagophila" (ORBIGNY) e "Australorbis glabratus" (SAY). Rev. bras. Biol., 17:17985, 1957.

25. STANDEN, O. D. The effect of temperature, light and salinity upon the hatcking of the ova of $\mathrm{S}$. mansoni Trans. R. Soc. trop. Med. Hyg., 45: 225-41, 1951.

26. STANDEN, O. D. Experimental infection of Australorbis glabratus with Schistosoma mansoni. I. - Individual and mass infection of snails, and the relationship of infection to temperature and season. Ann. trop. Med. Parasitol., $46: 48-52,1952$.

27. STURROCK, B, M. \& STURROCK, R. F. Laboratory studies of the host-parasite relationship of Schistosoma mansoni and Biomphalaria glabrata from St Lucia, West Indies, Ann. trop. Med. Parasitol., 64:357-63, 1970.

28. WRIGHT, C. A. \& ROSS, G. C. Electrophoretic studies of blood and egg proteins in Australorbis glabratus (Gastropoda, Planorbidae), Ann. trop. Med. Parasit., 57:47-51, 1963.

Recebido para publicação em 23/05/1977

Aprovado para publicaçāo em 14/07/1977 